\title{
High Serum Vaspin Concentrations in Patients with Ulcerative Colitis
}

Tomohito MORISAKI, MD, ${ }^{1}$ Fuminao TAKESHIMA, MD, PhD,${ }^{1}$ Hiroko FUKUDA, MD, ${ }^{1}$

Kayoko MATSUSHIMA, MD, PhD, ${ }^{1}$ Yuko AKAZAWA, $\mathrm{MD}, \mathrm{PhD},{ }^{1}$ Naoyuki YAMAGUCHI, MD, PhD, ${ }^{1}$ Ken OHNITA, MD, PhD, ${ }^{1}$ Hajime ISOMOTO, MD, PhD, ${ }^{1}$ Hiroaki TAKESHITA, MD, PhD, ${ }^{2}$ Terumitsu SAWAI, MD, PhD, ${ }^{2}$ Fumihiko FUJITA, MD, $\mathrm{PhD},{ }^{3}$ and Kazuhiko NAKAO, MD, $\mathrm{PhD}^{1}$

Department of Gastroenterology and Hepatology, Graduate School of Biomedical Sciences, Nagasaki University, Nagasaki, Japan

Division of Surgical Oncology, Department of Translational Medical Sciences, Nagasaki University Graduate School of Biomedical Sciences, Nagasaki, Japan

Department of Surgery, Nagasaki University Graduate School of Biomedical Sciences, Nagasaki, Japan

Corresponding author:

Fuminao Takeshima, $\mathrm{MD}, \mathrm{PhD}$

Department of Gastroenterology and Hepatology, Graduate School of Biomedical Sciences, Nagasaki

University, Nagasaki, Japan

1-7-1, Sakamoto, Nagasaki 852-8501, Japan

Tel: 81-95-819-7483; Fax: 81-95-849-7481; E-mail: ftake@nagasaki-u.ac.jp 


\section{ABSTRACT}

Background: Adipocytokines are associated with energy homeostasis and mediate various immune responses and inflammatory processes. Vaspin is a novel adipocytokine that is thought to exhibit anti-inflammatory effects.

Aims: We aimed to evaluate serum vaspin levels in inflammatory bowel disease (IBD) and determine its possible associations with the course and to clarify its intestinal localization. Methods: Serum samples were obtained from patients with Crohn's disease (CD; n = 30) and ulcerative colitis (UC; $n=33$ ) and from healthy volunteers (controls; $n=26)$. Enzymelinked immunosorbent assays were performed for all patients. Vaspin immunohistochemical staining was performed for intestines affected with IBD.

Results: Serum vaspin concentrations were significantly higher in patients with UC than in patients with CD and controls (422.9 \pm 361.9 vs. $163.4 \pm 116.2$ vs. $147.5 \pm 89.4$ pg/mL, respectively; $P<0.01)$. There was no difference in the serum vaspin concentrations between the patients with CD and controls. There was also no difference in the serum vaspin concentrations between the patients with active IBD and those with inactive IBD. However, the serum vaspin concentrations of most patients with UC increased after remission induction. Vaspin was expressed in the adipocytes of the mesenteric adipose tissues but not in the epithelial or inflammatory cells of large intestines of the patients with IBD.

Conclusions: Serum vaspin concentrations are elevated in patients with UC and increase further after remission induction, suggesting that vaspin may aid the auxiliary diagnosis of UC and may be useful for assessing disease activity in patients. 
KEYWORDS

Adipocytokine, Vaspin, Inflammatory bowel disease, Crohn’s disease, Ulcerative colitis 


\section{INTRODUCTION}

Since the discovery of leptin [1], the first adipocytokine, in 1994, adipose tissue has emerged as an important endocrine organ. Novel adipocytokines such as adiponectin [2,3], resistin [4], and visfatin [5] have been subsequently discovered. Adipose tissue has also been shown to secrete physically active substances such as tumor necrosis factor- $\alpha$ (TNF- $\alpha$ ) and plasminogen activator inhibitor-1 [6]. Adipocytokines function in both the metabolic and immune systems. In the former, they are involved in insulin sensitivity and resistance; in the latter, they exert inflammation-promoting and inflammation-inhibiting effects. Interestingly, adipocytokines secreted from the same adipose tissues can have completely opposite actions.

Although dramatic advances have been made in determining the pathology of inflammatory bowel diseases (IBD) such as Crohn’s disease (CD) and ulcerative colitis (UC), a clear cause remains elusive. The recent identification of the actions of adipocytokines on the metabolic and immune systems has raised questions regarding the associations between IBD, adipose tissues, and adipocytokines. It has long been recognized that hypertrophied mesenteric adipose tissues surround the periphery of the diseased intestine in CD [7]. These "fat wrapping" tissues cross over the mesenteric attachment and cover $\geq 50 \%$ of the intestinal periphery. However, the underlying cause and pathology of the CD-specific mesenteric adipose tissue enlargement have not been clearly elucidated. Desreumaux et al. [8] reported significant enhancements in the expression of peroxisome proliferator-activated receptor- $\gamma$, which plays an important role in fat synthesis, as well as the inflammation-promoting cytokine TNF- $\alpha$ within these enlarged mesenteric adipose tissues. Intestinal inflammation may be induced by the enhanced expression of TNF- $\alpha$ in these mesenteric adipose tissues. 
Various concentrations of serum adipocytokine were comparatively examined in patients with IBD, and their clinical applications were studied. Therefore, IBD and adipose tissues may be strongly associated with adipocytokines and may influence various etiologies and pathologies.

Vaspin is an adipocytokine that is expressed in the visceral fat tissues of the Otsuka LongEvans Tokushima Fatty rat (OLETF), an animal model of obesity and type 2 diabetes [9]. Vaspin is a serine protease inhibitor consisting of $412-415$ amino acids that exhibits $40.5 \%$ homology with $\alpha 1$-antitrypsin. Vaspin is also a pure adipocytokine that is not expressed in other organs. Animal studies have demonstrated that vaspin enhances insulin sensitivity and displays anti-inflammatory actions. However, no studies thus far, have reported on the association between vaspin and IBD. Herein, we aimed to elucidate the role of vaspin in IBD by measuring serum vaspin concentrations and clarifying its intestinal localization.

\section{MATERIALS AND METHODS}

\section{Patients}

We studied inpatients and outpatients treated at the Nagasaki University Hospital between August 2009 and May 2011. This study included 30 patients with CD and 33 patients with UC. Twenty-six healthy volunteers were recruited into the study as controls. No differences were noted in baseline characteristics such as gender and age. Nine patients with CD had a Crohn's disease activity index (CDAI) score $\geq 150$, while 8 patients with UC had a clinical activity index (CAI) score $\geq 6$. Infliximab and 5-aminosalicylic acid (5-ASA) formulations were the most common treatments administered to the patients with $C D$, while steroid immunosuppressants and 5-ASA were the most commonly used treatments in patients with 
UC (Table 1).

Serum samples were collected in ethylenediaminetetraacetic acid (EDTA) tubes and preserved at $-80^{\circ} \mathrm{C}$ until use.

Mesenteric adipose tissue specimens were obtained from 9 patients with UC, 9 with CD, and 7 with colon cancer who had undergone surgical resection. These samples were sonicated in Tissue Protein Extraction Reagent (T-PER; Thermo Scientific, Rockford, IL, USA) with a protease inhibitor (Calbiochem, San Diego, CA, USA). Homogenates were incubated for 10 min at $4^{\circ} \mathrm{C}$ and then centrifuged at $16,000 \mathrm{~g}$ for $10 \mathrm{~min}$ at $4^{\circ} \mathrm{C}$. The supernatants were collected and stored at $-80^{\circ} \mathrm{C}$ until use. The study protocol was approved by the medical ethics committee of Nagasaki University. Written informed consent was obtained from the participants in accordance with the Helsinki Declaration.

\section{Measurement of Vaspin Level}

Vaspin concentrations in serum and homogenate supernatants of adipose tissues were measured by enzyme-linked immunosorbent assay (ELISA) using a commercially available Human Vaspin ELISA Kit (Adipogen, Seoul, South Korea) according to the manufacturer's instructions. Total protein concentration in homogenate supernatants of adipose tissues was determined using Pierce ${ }^{\circledR}$ BCA Protein Assay Kit (Thermo Scientific) according to the manufacturer's instructions. The vaspin concentrations of adipose tissues were expressed in picograms of vaspin per milligram of total protein.

\section{Immunohistochemical Staining}

To confirm vaspin expression in the intestines and mesenteric adipose tissues, vaspin immunostaining was performed using tissue sections from patients with IBD who underwent 
intestinal resection. The sections were autoclaved for $15 \mathrm{~min}$ at $120^{\circ} \mathrm{C}$ in $10 \mathrm{mM}$ citrate buffer (pH 6) for antigen retrieval. The sections were then incubated with a rabbit anti-vaspin (63104) antibody (Phoenix Pharmaceuticals, Burlingame, CA, USA) diluted 1:500 overnight at $4^{\circ} \mathrm{C}$.

\section{Statistical Analysis}

For the statistical analysis, a Kruskal-Wallis test (Dunn’s post-hoc test) was used for multigroup comparisons, while a Mann-Whitney $U$ test, Wilcoxon signed-rank test, or Student's $t$-test was used for intergroup comparisons. Values of $P<0.05$ were considered statistically significant.

\section{RESULTS}

Elevated Serum Vaspin Concentrations in Patients with UC

The serum vaspin concentrations of the patients with UC were significantly increased compared to those of patients with $\mathrm{CD}$ and controls (422.9 \pm 361.9 vs. $163.4 \pm 116.2$ vs. $147.5 \pm 89.4 \mathrm{pg} / \mathrm{mL}$, respectively; $P<0.01)$. The serum vaspin concentrations did not differ significantly between the patients with CD and controls (Table 1, Figure 1).

Differences in the serum vaspin levels were then evaluated according to disease activity. In the patients with $\mathrm{CD}$, there was no significant association between the CDAI scores and serum vaspin levels (Figure 2A). Likewise, in the patients with UC, there was no association between the CAI scores and serum vaspin levels (Figure 2B). The serum vaspin levels were not significantly associated with disease extent and clinical course in the patients with UC. In addition, the serum vaspin levels were not significantly associated with white blood cell (WBC) counts and C-reactive protein (CRP) levels in the patients with CD or UC. Moreover, 
the serum vaspin levels were not significantly associated with the body mass index values of the $\mathrm{CD}$, UC, or control groups.

We compared the serum vaspin levels in the same patients at acute relapse (before treatment) and after the induction of remission (after treatment; administration of prednisolone, tacrolimus, 5-ASA, cyclosporine, azathioprine and/or leukocytapheresis). All 11 patients with UC (CAI scores $\geq 6)$ had increased serum vaspin levels after treatment $(P<$ 0.01) (Figure 3). In order to examine whether the vaspin increase was treatment-specific, we divided patients into 2 subgroups according to the treatment regimen: steroid group $(n=6)$ and other medication group $(n=5)$. In both groups, the serum vaspin levels significantly increased after treatment $(\mathrm{p}<0.05)$ (Figure 4).

Vaspin Expression in the Mesenteric Adipose Tissue Adipocytes of Patients with IBD

To identify the localization of vaspin, immunostaining was performed for tissue sections from patients with IBD who had undergone intestinal resection. Vaspin was strongly expressed in the adipocytes but not in stromal vessels of the mesenteric adipose tissues or the epithelial and inflammatory cells of the large intestines of the patients with UC and CD (Figure 6).

\section{Vaspin Concentration in Mesenteric Adipose Tissue}

The mean vaspin concentration in mesenteric adipose tissues of patients with UC was higher than that in patients with colon cancer or CD, similar to the serum vaspin concentrations. However, these differences were not significant (Figure 5).

\section{DISCUSSION}

Numerous studies have evaluated serum adipocytokine concentrations in patients with 
IBD. Luzia et al. [10] reported that patients with active UC had significantly higher serum concentrations of resistin and visfatin compared to healthy subjects and patients with CD, and that the serum adiponectin concentrations were significantly lower in the patients with CD and UC than in healthy subjects. Nishi et al. [11] reported that the serum leptin concentrations were not significantly different between patients with CD, patients with UC, and healthy subjects.

The current study is the first to measure the vaspin concentrations of serum and mesenteric adipose tissue in patients with IBD. The serum vaspin concentrations were significantly higher in patients with UC than in patients with CD and healthy subjects. The vaspin concentrations in mesenteric adipose tissues of patients with UC were also higher than those in patients with CD or colon cancer. Recent clinical studies have reported high serum vaspin levels in patients with type 2 diabetes [12], non-alcoholic fatty liver disease (NAFLD) [13], and chronic rheumatoid arthritis [14] and low vaspin concentrations in patients with ischemic heart disease [15] and chronic hepatitis C [16] relative to healthy subjects. No difference in serum vaspin levels was detected in patients with Kawasaki disease [17], Behcet’s syndrome [14], and psoriasis [18]. These differences may suggest that serum vaspin concentrations are disease-specific to some extent. Since the vaspin concentrations were high only in the patients with UC and not in those with $\mathrm{CD}$, the evaluation of vaspin concentration may be helpful in the auxiliary diagnosis of UC and for differentiating between CD and UC.

Although serum vaspin levels do not appear to be associated with disease activity in CD or UC, their increase was parallel to the clinical improvement observed in patients after treatment, suggesting that this measurement may become an index of treatment efficacy in 
patients. The observed upregulation of vaspin may reflect the suppression of inflammation after treatment. Auguet et al. [19] showed an inverse association of vaspin with inflammatory mediators such as IL-6 and lipocalin 2. Ozgen et al. [14] also demonstrated a positive association of vaspin with adiponectin, which has an anti-inflammatory effect. Considering that proinflammatory and anti-inflammatory adipocytokines coexist in the same adipose tissues, a type of feedback mechanism may function among adipocytokines. Recently, Klaasen et al. [20] demonstrated that glucocorticoid treatment resulted in increased serum adiponectin, leptin, and vaspin levels in patients with rheumatoid arthritis, although adalimumab treatment did not alter these levels. The investigators speculated that the changes in the adipocytokine levels in their cases were treatment-specific. When we compared the steroid group and the other medication group in the present study, the serum vaspin levels significantly increased after treatment in both groups. Although we did not have a sufficiently high number of patients with UC on treatment with simple medications, we could not determine the treatment-specific effect reflected by the increase in vaspin concentration. Larger prospective studies comparing changes in vaspin levels in patients with UC after the initiation of glucocorticoid treatment to that after other treatments are essential to clarify the effects of specific treatment regimens or the clinical course on vaspin levels.

It remains uncertain which cells are responsible for increased serum vaspin levels in patients with UC. Lee et al. [21] demonstrated that vaspin mRNA expression was adipocytespecific in abdominal adipose tissue. The current study confirmed vaspin protein expression in adipocytes but not in stromal vessels of IBD mesenteric adipose tissues by immunostaining. Recently, Saalbach et al. [18] demonstrated that vaspin protein was expressed not only in 
adipose tissue but also in keratinocytes of human skin. However, in this study, we could not observe vaspin expression in the epithelium of the large intestines in patients with IBD. The major source of intestinal vaspin is likely the mesenteric adipose tissue-derived adipocytes.

Hida et al. [9] demonstrated that recombinant vaspin administration improved insulin sensitivity and glucose tolerance, decreased the gene expression of proinflammatory adipocytokines such as leptin, resistin, and TNF- $\alpha$, and increased the expression of the antiinflammatory adipocytokine adiponectin in obese mice. Vaspin may be involved in the regulation of intestinal inflammation. Because of vaspin can suppress the expression of proinflammatory adipocytokines such as TNF- $\alpha$ [22], it may exhibit anti-inflammatory actions against intestinal inflammation and is expected to become a future therapeutic target. 


\section{REFERENCES}

Zhang Y, Proenca R, Maffei M, et al. Positional cloning of the mouse obese gene and its human homologue. Nature. 1994; 372: 425-432.

Maeda K, Okubo K, Shimomura I, et al. cDNA cloning and expression of a novel adipose specific collagen-like factor, apM1 (AdiPose Most abundant Gene transcript 1). Biochem Biophys Res Commun. 1996; 221: 286-289.

Arita Y, Kihara S, Ouchi N, et al. Paradoxical decrease of an adipose-specific protein, adiponectin, in obesity. Biochem Biophys Res Commun. 1999; 257: 79-83.

Steppan CM, Bailey ST, Bhat S, et al. The hormone resistin links obesity to diabetes. Nature. 2001; 409: 307-312.

Fukuhara A, Matsuda M, Nishizawa M, et al. Visfatin: a protein secreted by visceral fat that mimics the effects of insulin. Science. 2005; 307: 426-430.

Maeda K, Okubo K, Shimomura I, et al. Analysis of an expression profile of genes in the human adipose tissue. Gene. 1997; 190: 227-235.

Sheehan AL, Warren BF, Gear MW, et al. Fat-wrapping in Crohn's disease: pathological basis and relevance to surgical practice. Br J Surg. 1992; 79: 955-958.

Desreumaux P, Ernst O, Geboes K, et al. Inflammatory alterations in mesenteric adipose tissue in Crohn's disease. Gastroenterology. 1999; 117: 73-81.

Hida K, Wada J, Eguchi J, et al. Visceral adipose tissue-derived serine protease inhibitor: a unique insulin-sensitizing adipocytokine in obesity. Proc Natl Acad Sci U S A. 2005; 102: 10610-10615.

Valentini L, Wirth EK, Schweizer U, et al. Circulating adipokines and the protective effects 
of hyperinsulinemia in inflammatory bowel disease. Nutrition. 2009; 25: 172-181.

Nishi $\mathrm{Y}$, Isomoto $\mathrm{H}$, Ueno $\mathrm{H}$, et al. Plasma leptin and ghrelin concentrations in patients with Crohn's disease. World J Gastroenterol. 2005; 11: 7314-7317.

El-Mesallamy HO, Kassem DH, El-Demerdash E, et al. Vaspin and visfatin/Nampt are interesting interrelated adipokines playing a role in the pathogenesis of type 2 diabetes mellitus. Metabolism. 2011; 60: 63-70.

Aktas B, Yilmaz Y, Eren F, et al. Serum levels of vaspin, obestatin, and apelin-36 in patients with nonalcoholic fatty liver disease. Metabolism. 2011; 60: 544-549.

Ozgen M, Koca SS, Dagli N, et al. Serum adiponectin and vaspin levels in rheumatoid arthritis. Arch Med Res. 2010; 41: 457-463.

Kadoglou NP, Gkontopoulos A, Kapelouzou A, et al. Serum levels of vaspin and visfatin in patients with coronary artery disease-Kozani study. Clin Chim Acta. 2011; 412: 48-52.

Kukla M, Zwirska-Korczala K, Gabriel A, et al. Chemerin, vaspin and insulin resistance in chronic hepatitis C. J Viral Hepat. 2010; 17: 661-667.

Fioravanti A, Simonini G, Cantarini L, et al. Circulating levels of the adipocytokines vaspin and omentin in patients with Kawasaki disease. Rheumatol Int. 2012; 32: 1481-1482.

Saalbach A, Vester K, Rall K, et al. Vaspin--a link of obesity and psoriasis? Exp Dermatol. 2012; 21: 309-312.

Auguet T, Quintero Y, Riesco D, et al. New adipokines vaspin and omentin. Circulating levels and gene expression in adipose tissue from morbidly obese women. BMC Medical Genetics. $2011 ; 12: 60$.

Klaasen R, Herenius MM, Wijbrandts CA, et al. Treatment-specific changes in circulating 
adipocytokines: a comparison between tumour necrosis factor blockade and glucocorticoid treatment for rheumatoid arthritis. Ann Rheum Dis. 2012; 71: 1510-1516.

Lee JA, Park HS, Song YS, et al. Relationship between vaspin gene expression and abdominal fat distribution of Korean women. Endocr J. 2011; 58: 639-646.

Phalitakul S, Okada M, Hara Y, et al. Vaspin prevents TNF- $\alpha$-induced intracellular adhesion molecule- 1 via inhibiting reactive oxygen species-dependent NF-kB and $\mathrm{PKC} \theta$ activation in cultured rat vascular smooth muscle cells. Pharmacol Res. 2011; 64: 493-500. 


\section{FIGURE LEGENDS}

\section{Figure 1}

Comparison of serum vaspin levels between patients with ulcerative colitis (UC) or Crohn's disease (CD) and controls. Serum vaspin levels of the patients with UC were significantly higher than those of patients with CD or controls.

\section{Figure 2A}

Comparison of serum vaspin levels of patients with CD and disease activity (indicated by Crohn's Disease Activity Index [CDAI]). No statistically significant differences were observed.

Figure 2B

Comparison of serum vaspin levels of patients with UC and disease activity (indicated by clinical activity index [CAI]). No statistically significant differences were observed.

Figure 3

Comparison of serum vaspin concentrations between patients in active and remission stages. Administration of prednisolone, tacrolimus, 5-ASA, cyclosporine and/or azathioprine and/or leukocytapheresis resulted in increased serum vaspin concentrations in all 11 patients with UC. Each symbol indicates 1 patient.

Figure 4A

Comparison of serum vaspin concentrations between patients in active and remission stages in the steroid group (the treatment regimen that included steroids).Vaspin concentrations significantly increased in all 6 patients.

PSL: prednisolone 
Figure 4B

Comparison of serum vaspin concentrations between patients in active and remission stages in the other medication group (the treatment regimen that did not include steroids). Vaspin concentrations significantly increased in all 5 patients.

PSL: prednisolone

Figure 5

Comparison of vaspin concentrations in mesenteric adipose tissues between the patients with ulcerative colitis (UC) or Crohn's disease (CD) and colon cancer (CC). The vaspin concentration in mesenteric adipose tissues of patients with UC was higher than that in patients with $\mathrm{CD}$ or $\mathrm{CC}$, similar to the serum vaspin concentrations. However, these differences were not significant.

Figure 6

Immunohistochemical vaspin staining of the mesenteric adipose tissue (Figures 6A, 6B) and colonic epithelium (Figure 6C) of the patients with UC. Vaspin expression was noted in the adipocytes (arrow head) of the mesenteric adipose tissue 
Figure 1.

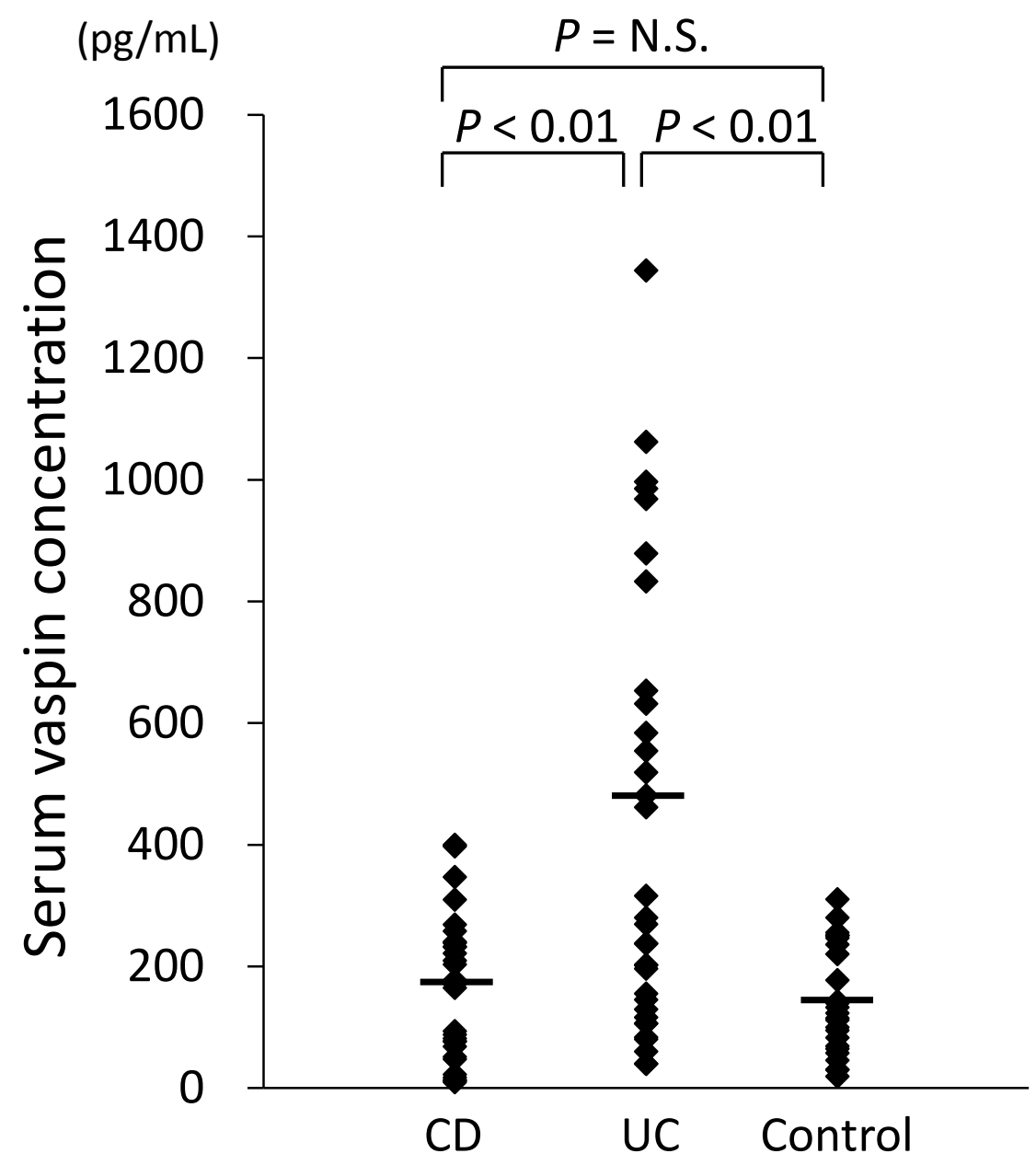


Figure 3

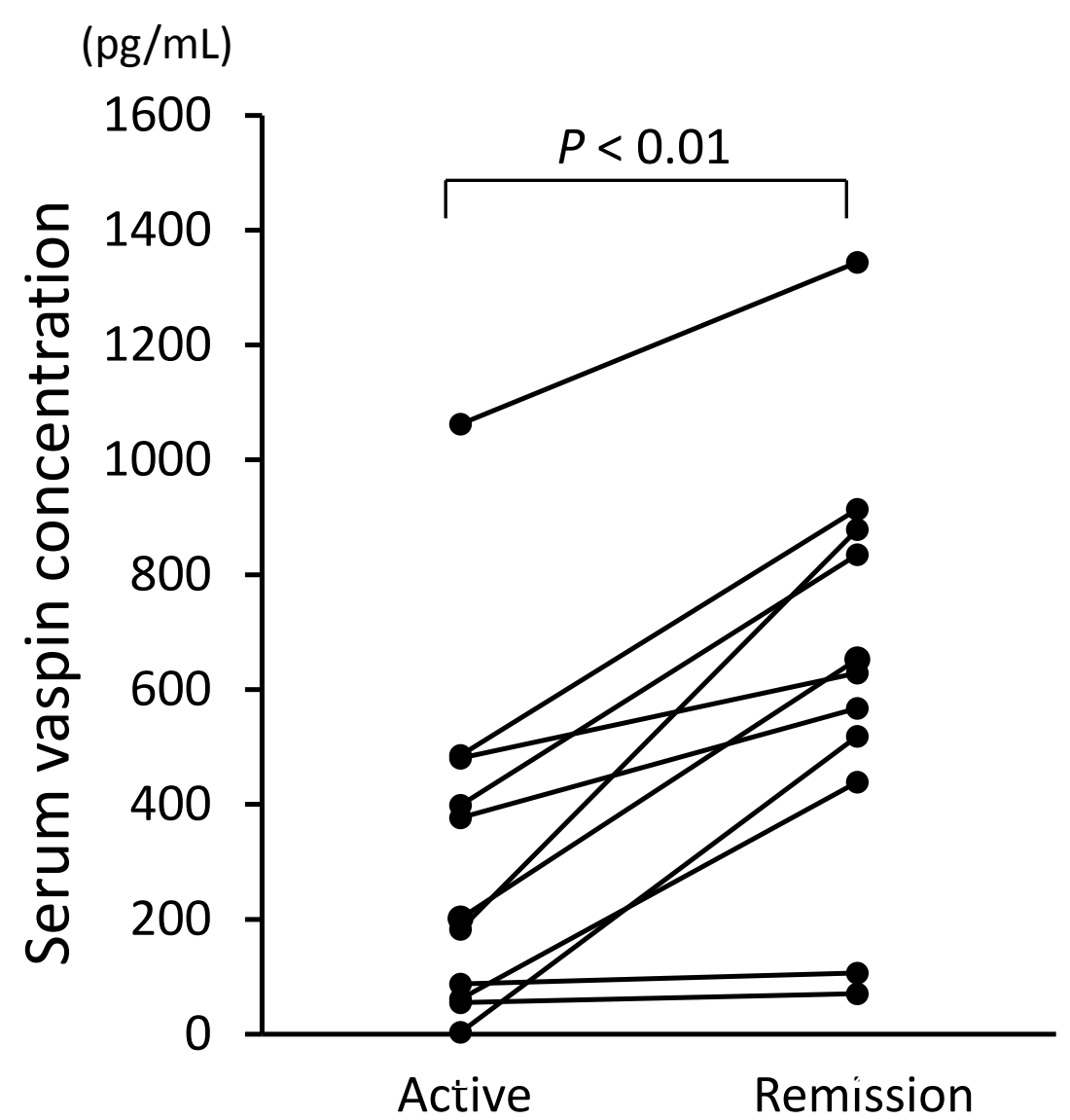


Figure 4A

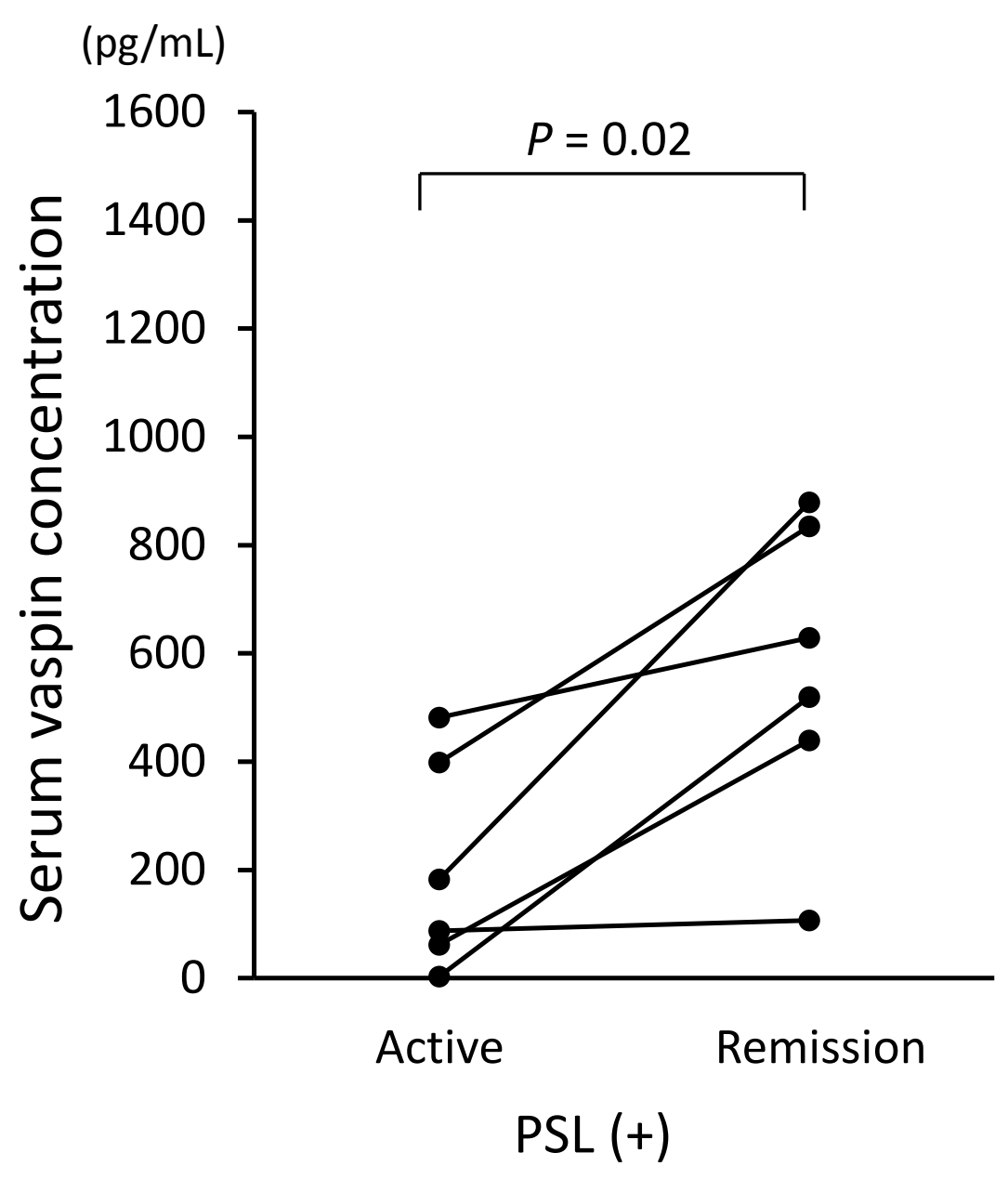

Figure 4B

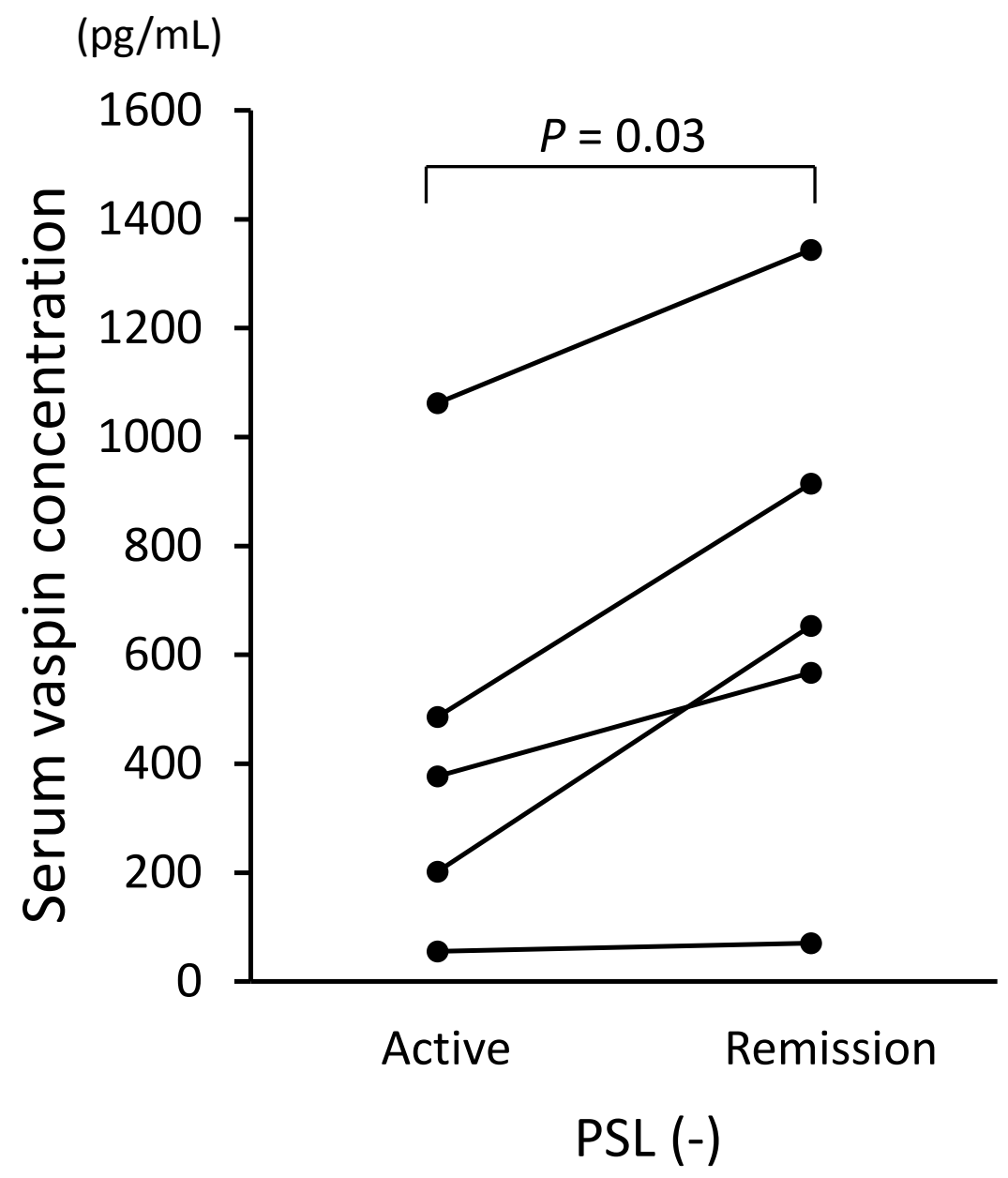


Figure 5

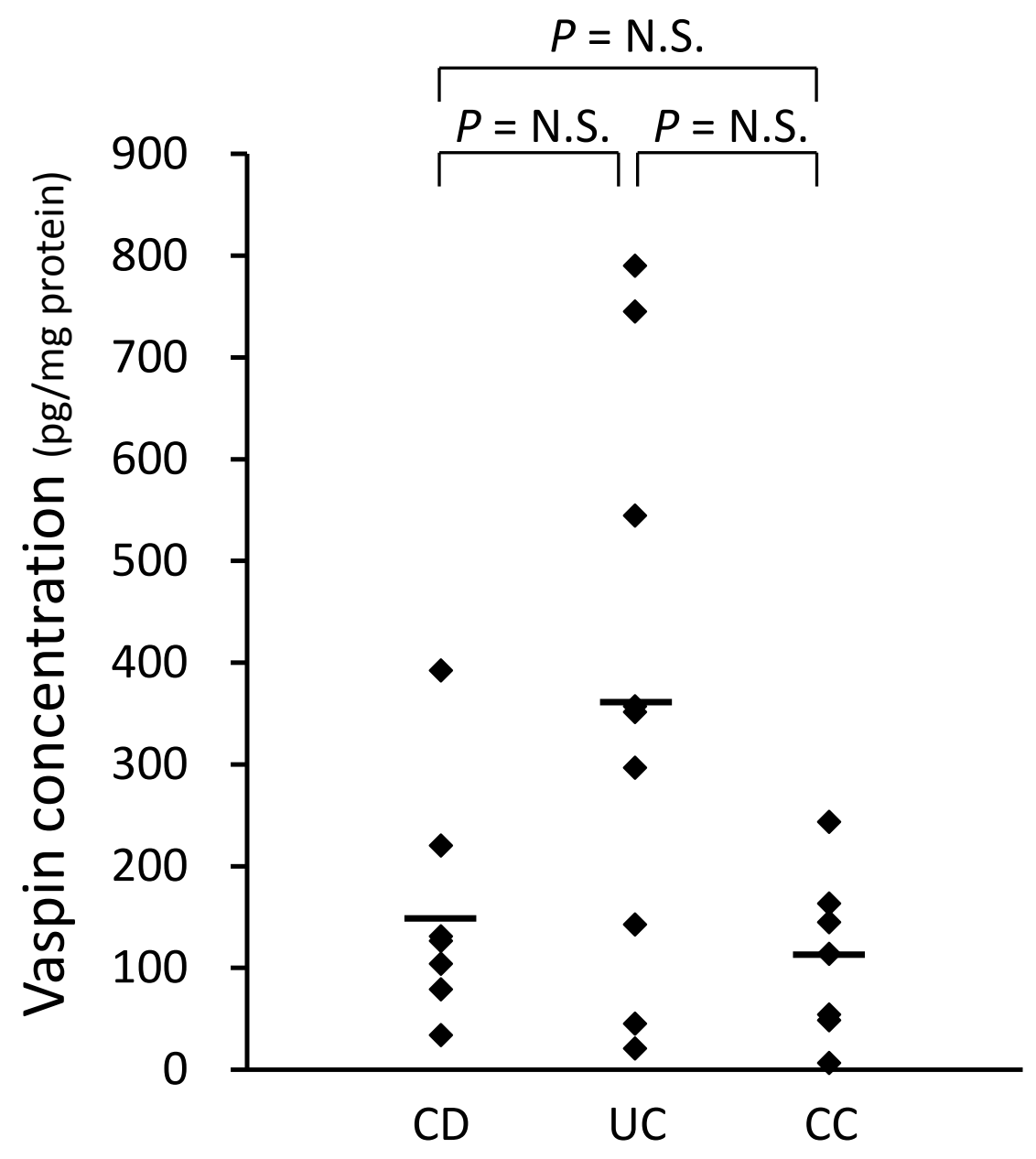


